Pesq. Vet. Bras. 37(10):1165-1171, outubro 2017 DOI: $10.1590 / \mathrm{S} 0100-736 \mathrm{X} 2017001000020$

\title{
Aspectos ultrassonográficos, anatômicos e histológicos normais da articulação metacarpofalangeana equina ${ }^{1}$
}

\author{
Grasiela De Bastiani ${ }^{2 *}$, Flavio De La Corte ${ }^{2}$, Glaucia D. Kommers ${ }^{3}$, Karin E. Brass², \\ Roberta Pereira ${ }^{2}$, Camila Cantarelli ${ }^{2}$ e Taiara M. da Silva ${ }^{3}$
}

\begin{abstract}
De Bastiani G., De La Corte F., Kommers G.D., Brass K.E., Pereira R., Cantarelli C. \& Silva T.M. 2017. [Normal ultrasonographic, anatomical and histological aspects of the equine metacarpophalangeal joint.] Aspectos ultrassonográficos, anatômicos e histológicos normais da articulação metacarpofalangeana equina. Pesquisa Veterinária Brasileira 37(10):1165-1171. Departamento de Clínica de Grandes Animais, Universidade Federal de Santa Maria, Avenida Roraima 1000, Santa Maria, RS 97105-900, Brazil. E-mail: grasibage@hotmail.com

The purpose of this study was to describe and characterize the equine metacarpophalangeal joint structures through ultrasonographic, anatomical and histological analysis. Seventy forelimb specimens were obtained from a slaughterhouse and submitted to ultrasonographic evaluation. Thirty specimens without ultrasonographic detectable lesions were selected for dissection and subsequent anatomical and histological evaluation. Criteria such as size, shape, architecture and echogenicity were observed in order to characterize normal ligaments, tendons, joint capsule and articular cartilage of the metacarpophalangeal joint.
\end{abstract}

INDEX TERMS: Ultrasonography, anatomy, histology, equine, metacarpophalangeal joint, images, ultrasound.

RESUMO.- 0 objetivo deste estudo foi descrever e caracterizar as estruturas que compõem a articulação metacarpofalangena equina por meio de análise ultrassonográfica, anatômica e histológica. Membros torácicos equinos $(=70)$, obtidos em instalações frigoríficas, foram submetidos a exame ultrassonográfico post mortem. Destes, 30 membros apresentaram imagens ultrassonográficas consideradas sem alterações. Posteriormente foi realizada a dissecação dos mesmos e o estudo anátomo-histológico. Critérios como tamanho, forma, arquitetura e ecogenicidade foram observados a fim de caracterizar as imagens ultrassonográficas, anatômicas e histológicas normais das estruturas ligamentares, tendíneas, capsulares e cartilaginosas da articulação metacarpofalangeana equina.

TERMOS DE INDEXAÇÃO: Ultrassonografia, anatomia, histologia, articulação metacarpofalangeana, equina, imagem, ultrassom.

\footnotetext{
Recebido em 26 de maio 2016.

Aceito para publicação em 6 de abril de 2017

${ }^{2}$ Departamento de Clínica de Grandes Animais, Hospital Veterinário Universitário (HVU), Universidade Federal de Santa Maria (UFSM), Av. Roraima 1000, Campus Universitário, Santa Maria, RS 97105-900, Brasil. *Autor para correspondência: grasibage@hotmail.com

${ }^{3}$ Departamento de Patologia, Centro de Ciências da Saúde (CCS), UFSM, Av. Roraima 1000, Campus Universitário, Santa Maria, RS 97105-900, Brasil.
}

\section{INTRODUÇÃO}

A articulação metacarpofalangeana (MF) é uma das articulações mais afetadas por lesões traumáticas e degenerativas em equinos e por isso é frequentemente submetida a avaliações radiográficas e ultrassonográficas (Denoix 1996). Funcionalmente, essa articulação é especializada na realização de movimentos de flexão e extensão no plano sagital devido à forma do côndilo do terceiro metacarpiano/metatarsiano, à presença de uma proeminente crista sagital e à força congruente dos ligamentos que a cercam (Barone 1989).

No aspecto dorsal, a articulação MF possui uma cápsula espessa que mede aproximadamente $1 \mathrm{~mm}$ na sua inserção proximal e $0,5 \mathrm{~mm}$ na distal. A superfície da cartilagem articular e do osso subcondral pode ser visualizada com o membro na posição vertical, apoiado sobre o solo. Porém, para avaliar a porção distal destas estruturas, se torna necessária a flexão máxima da articulação. Além do ligamento suspensório (LS), ossos sesamoides proximais e ligamento intersesamoideano (LI), esta articulação ainda apresenta dois ligamentos colaterais (LC) simétricos formados por duas camadas, uma superficial ou longa e outra profunda, curta e oblíqua. Ela também possui um recesso proximal dorsal fibroso que contém pouco líquido sinovial em 
articulações sadias e outro recesso proximal palmar com inúmeras vilosidades sinoviais (Denoix 2009). A face palmar do boleto se caracteriza pelo ligamento anular palmar (LAP)/plantar localizado imediatamente abaixo da pele e tecido subcutâneo. Além disso, as bordas do fino tendão flexor digital superficial (TFDS) estão em estreito contato com o tendão flexor digital profundo (TFDP) oval. Juntamente a eles se observa a manica flexora que desliza em conjunto sobre o scutum proximal composto pelo ligamento intersesamoideano e os dois ossos sesamoides proximais (Seignour et al. 2012).

A ultrassonografia é o principal método amplamente disponível de diagnóstico por imagem para avaliar e diagnosticar lesões de tecidos moles, incluindo a possibilidade ímpar de avaliar enteses. Ela permite o estudo em tempo real e dinâmico avaliando tamanho, arquitetura, forma e ecogenicidade das estruturas (Denoix 2000).

0 propósito deste estudo foi descrever e caracterizar as estruturas normais que compõem a articulação MF equina, utilizando a ultrassonografia, anatomia e histologia. Os dados obtidos são fundamentais para a correta interpretação ultrassonográfica de alterações da articulação MF equina.

\section{MATERIAL E MÉTODOS}

Setenta espécimes torácicos equinos, direito e esquerdo, desarticulados na articulação intercarpiana foram obtidos em um frigorífico da região sul do Brasil. Destes, 30 foram selecionados por apresentarem imagens ultrassonográficas consideradas normais das articulações MF, bem como por não apresentarem alterações físicas à inspeção e palpação tais como distensão da bainha digital, alterações nos ramos do LS e efusão articular.

Os espécimes torácicos equinos selecionados foram levados ao laboratório da Universidade Federal de Santa Maria, onde foi realizada a tricotomia e a imersão em água morna, que favorece a absorção hídrica pelos tecidos cutâneos, permitindo uma melhor transmissão das ondas ultrassonográficas entre o transdutor e a estrutura a ser examinada. Foi aplicado gel ecográfico sobre a pele em quantidade suficiente para evitar interferências na propagação do som quando o transdutor era colocado sobre a mesma.

Os estudos ultrassonográficos realizados na região MF foram executados com o membro na posição vertical, apoiado sobre o solo e estendido. Imagens ultrassonográficas transversais e longitudinais foram obtidas usando as abordagens palmar, dorsal, palmar oblíqua, dorsomedial e dorsolateral. As imagens foram obtidas utilizando um equipamento de ultrassom portátil (Myndrai 2200), equipado com um transdutor linear de 7-10 MHz e um "standoff pad".

Na face dorsal do boleto (Fig.1A) foi realizada uma secção ecográfica transversal para avaliar a metade proximal do côndilo metacarpiano. 0 transdutor foi deslocado no sentido próximo-distal da metáfise do osso metacarpiano III (McIII) até a falange proximal para observação da inserção da cápsula articular.

Secções ecográficas longitudinais no plano parasagital (Fig.1B e 1C) foram realizadas na face dorsomedial e dorsolateral da articulação MF a fim de avaliar o LC correspondente. Da mesma forma, no aspecto medial e lateral, na altura da base dos ossos sesamoides proximais, foram produzidas imagens transversais (Fig.1D) e longitudinais (Fig.1E) do LS.

Na secção transversal da face palmar (Fig.1F) da articulação $\mathrm{MF}$, o transdutor foi movido lateral e medialmente para obter imagens do LAP. 0 transdutor foi inclinado para baixo e para cima, a fim de produzir imagens negativas e positivas facilitando a visuali- zação de áreas cicatriciais nos tendões flexores. Macroscopicamente, a espessura do LAP foi medida com auxílio de um paquímetro.

Posteriormente ao exame ultrassonográfico, os espécimes torácicos foram dissecados e submetidos a um estudo macroscópico detalhado das estruturas avaliadas. Critérios como tamanho, forma, consistência, presença de aderências e coloração foram registrados. Os achados macroscópicos foram documentados e fotografados, colhidos e fixados em solução de formol a $10 \%$ por um período de 14 dias. Tecidos moles sofreram o processamento de rotina para histologia. Os tecidos ósseos, após a fixação, passaram pela descalcificação em solução aquosa de citrato de ácido sódico e fórmico e foram rotineiramente preparados para histologia. As lâminas foram preparadas $(3 \mu \mathrm{m})$ e coradas pela técnica de hematoxilina-eosina.

\section{RESULTADOS}

Nos 30 membros avaliados, 36 estruturas normais foram avaliadas pelas técnicas ecográficas e anátomo-histológicas. Estas 36 estruturas incluíram cápsula articular $(\mathrm{n}=10)$, cartilagem articular do McIII $(n=2)$, tendões $(n=11)$ e ligamentos ( $\mathrm{n}=13)$.

\section{Face dorsal}

Na secção ultrassonográfica transversal da face dorsal da articulação MF a superfície articular do osso subcondral do McIII se apresenta como uma superfície óssea lisa hiperecogênica. A imagem da cartilagem articular, que recobre a superfície do osso subcondral do McIII como uma camada de proteção, é representada ultrassonograficamente como uma estrutura anecóica e regular. Neste local também se observa uma estrutura ecogênica que recobre a membrana sinovial e a cápsula articular, que se torna assimétrica no seu aspecto medial e lateral (Fig.2A e Fig.3A). Em condições fisiológicas, é difícil identificar a superfície subcondral do McIII macroscopicamente, pois a mesma está coberta pela cartilagem articular, uma camada brilhante e lisa de coloração branco amarelada (Fig.2B). Na articulação foi observada pequena quantidade de líquido sinovial. Microscopicamente, o osso subcondral apresenta canais minúsculos (contendo prolongações citoplasmáticas celulares) que atravessam o osso se estendendo de uma superfície óssea a outra onde estão localizados os capilares. Acima do osso subcondral, três camadas cartilaginosas podem ser identificadas; uma profunda que delimita o osso subcondral cujos condrócitos estão dispostos de forma vertical e cujo arranjo de fibras de colágeno é radial. Cobrindo esta, há a camada intermediária em que os condrócitos são maiores e as fibras de colágeno são orientadas de forma aleatória. E por último, a camada superficial apresenta condrócitos achatados ou ovoides e fibras de colágeno dispostas tangencialmente (Fig.2C). Na avaliação macroscópica e histológica, a cápsula articular se apresenta como uma estrutura fibrocartilaginosa de coloração esbranquiçada (Fig.3B), rica em fibras de colágeno e sinoviócitos, que podem ser observados em sua periferia (Fig.3C). Esta estrutura é pouco elástica contribuindo desta forma para manter a estabilidade da articulação. 0 espessamento da cápsula articular ( 2 a $3 \mathrm{~mm}$ ) foi um achado comum avaliado por meio da mensuração ultrassonográfica e confirmado macroscopicamente por meio do paquímetro. A membrana sinovial que se localiza na camada interna da 

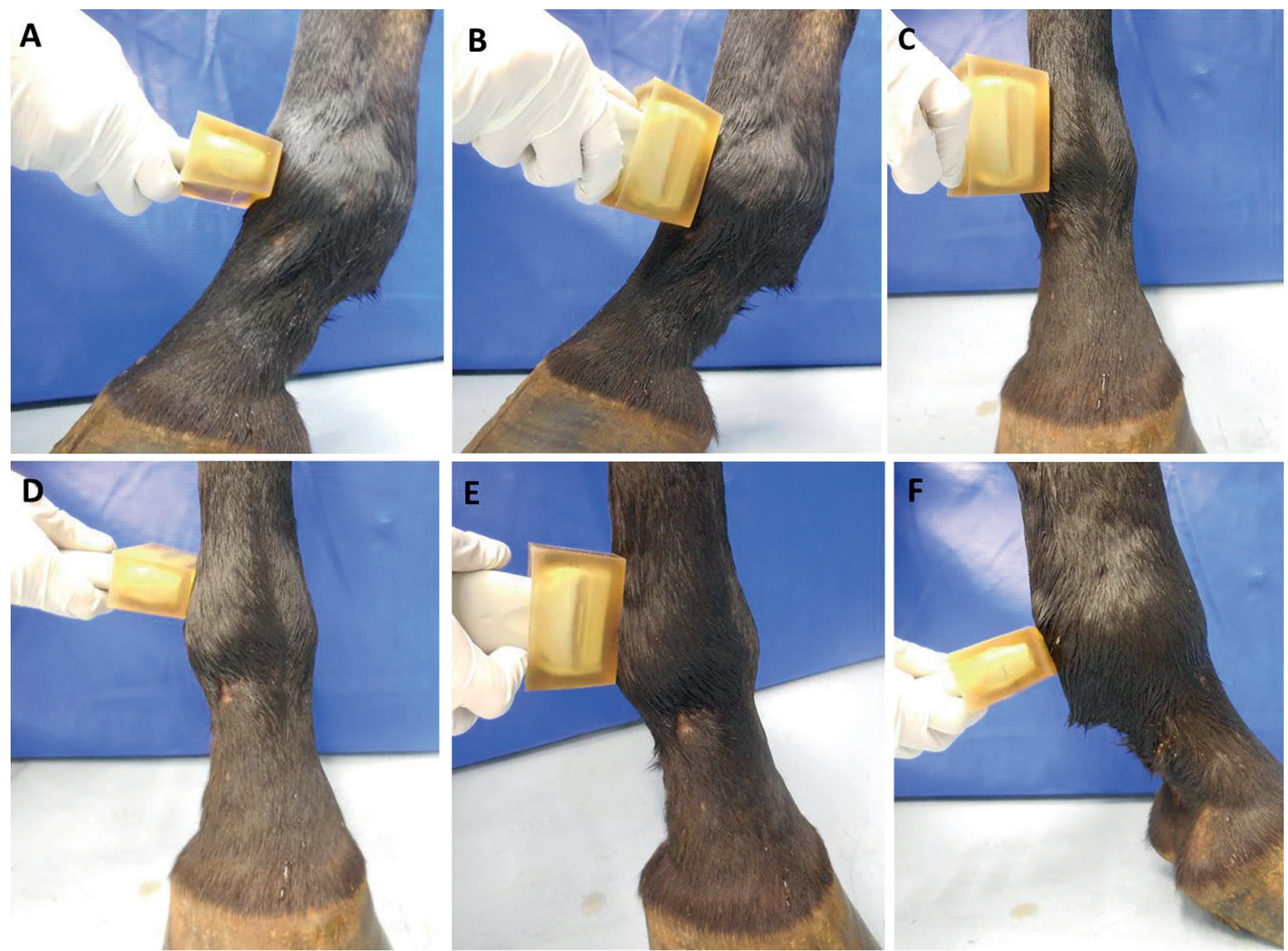

Fig.1. (A) Secção ultrassonográfica transversal da face dorsal da articulação MF. (B) Secção longitudinal parasagital do ligamento colateral lateral da articulação MF [transdutor situado na fossa condilar abaxial do McIII para a visualização da parte curta ou profunda do ligamento colateral da articulação MF]. (C) Secção longitudinal parasagital do ligamento colateral lateral [parte superficial ou longa] da articulação MF [face dorsolateral da articulação MF]. (D) Secção ultrassonográfica transversal do ligamento suspensório [face medial da articulação MF e abaxial do osso sesamoide proximal medial]. (E) Secção ultrassonográfica longitudinal parasagital do ligamento suspensório [face medial da articulação MF]. (F) Secção ultrassonográfica transversal da face palmar da articulação MF.
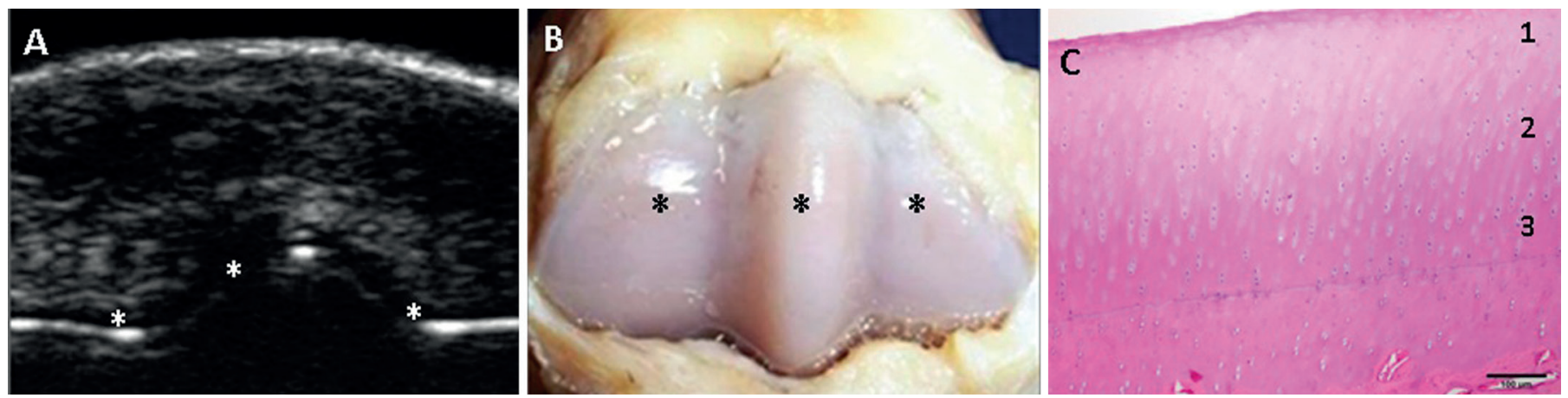

Fig.2. (A) Secção ultrassonográfica transversal da face dorsal da articulação MF. Medial para esquerda e lateral para a direita. A cartilagem articular é representada pela linha regular anecóica recobrindo a superfície óssea do MCIII [asterisco]. (B) Imagem macroscópica da cartilagem articular esbranquiçada brilhante cobrindo o côndilo do McIII e crista sagital [asterisco]. (C) Secção transversal histológica ilustrando as três camadas da cartilagem articular: Camada superficial [1], Camada intermediária [2], Camada profunda [3].

cápsula articular é uma estrutura extremamente fina de coloração rosa claro em condições normais e possui uma quantidade abundante de vasos sanguíneos, linfáticos e nervos. Os sinoviócitos se concentram ao longo de toda a extensão do bordo interno da membrana, estando interligados entre as fibras de colágeno (Fig.3). 

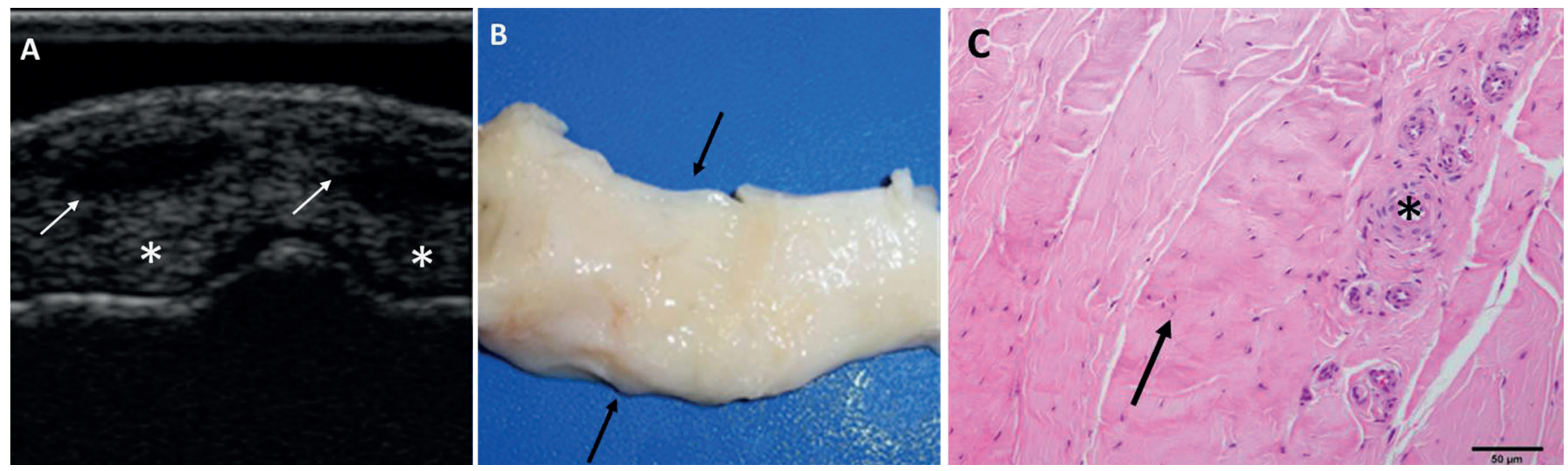

Fig.3. (A) Secção ultrassonográfica transversal da face dorsal da articulação MF. Medial para a esquerda e lateral para a direita. Cápsula articular ecogênica [asterisco] recobrindo a cartilagem articular do côndilo do McIII no aspecto medial e lateral e localizada abaixo dos tendões extensor dorsal e extensor lateral do dedo [seta]. (B) Superfície externa da cápsula articular. (C) Secção longitudinal histológica da cápsula articular. Fibras de colágeno [seta] e sinoviócitos [asterisco].
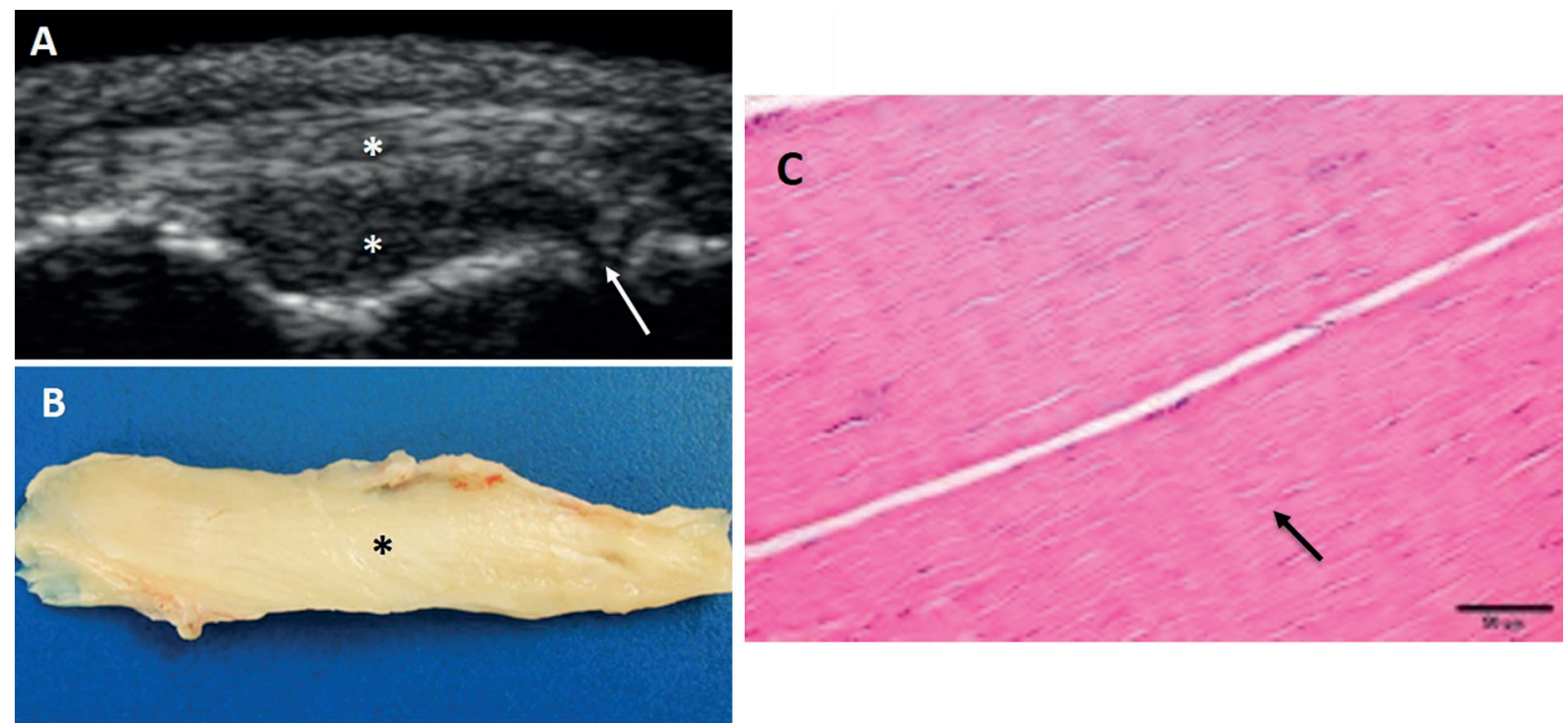

Fig.4. (A) Secção ultrassonográfica longitudinal da face lateral da articulação MF. Proximal para a esquerda e distal para a direita. Parte superficial do LC ecogênica [asterisco]. Parte profunda do LC hipoecogênica ocupando a fossa condilar [asterisco]. Espaço articular [seta]. (B) Parte superficial do LC dissecada [asterisco]. (C) Secção longitudinal histológica da parte superficial do LC. Note o arranjo ondulado das fibras de colágeno [seta].

\section{Face dorsolateral e dorsomedial}

Na secção longitudinal, após a localização da fossa colateral lateral ou medial dos côndilos metacarpianos se observa os LCs compostos por duas partes. Uma, superficial ou longa, apresenta fibras longitudinais que percorrem a porção lateral distal do McIII chegando às eminências da primeira falange. A outra, profunda ou curta, situada palmar à parte superficial se aloja na fossa condilar abaxial do McIII com arranjo fibrilar oblíquo. As fibras da parte superficial ou longa são ecogênicas e estão dispostas de forma paralela, sendo facilmente avaliadas. A parte profunda ou curta do ligamento apresenta ecogenicidade menor que a superficial, com uma arquitetura organizada em pontos longilíneos (Fig.4A).

Macroscopicamente a parte superficial ou longa apresenta uma espessura que varia de $1 \mathrm{a} 2 \mathrm{~mm}$ apresentando coloração branca amarelada (Fig.4B). Ela é facilmente identificada após a dissecação dos ramos lateral/medial do ligamento suspensório e se liga a parte profunda ou curta do LC na fossa condilar. Histologicamente as fibras de colágeno estão arranjadas em ondas paralelas e são compostas por colágeno (Fig.4C).

\section{Face medial e lateral}

Na secção transversal, os ramos distais do LS são facilmente identificados após a localização dos ossos sesamoides proximais na face lateral ou medial. Eles possuem uma forma trapezoide na sua inserção nos bordos apical e abaxial dos ossos sesamoides proximais. A sua aparência é ecogênica e apresenta bordos bem delimitados (Fig.5A). Na secção longitudinal, as fibras possuem orientação linear e paralela. Nesta secção é comum haver falta de contato entre o transdutor e a pele resultando em imagens com falta de paralelismo das fibras. 0 transdutor deve ser movido no sentido dorso palmar a fim de evitar falsos diagnósticos. Os ramos distais do LS se localizam abaxiais ao recesso palmar 

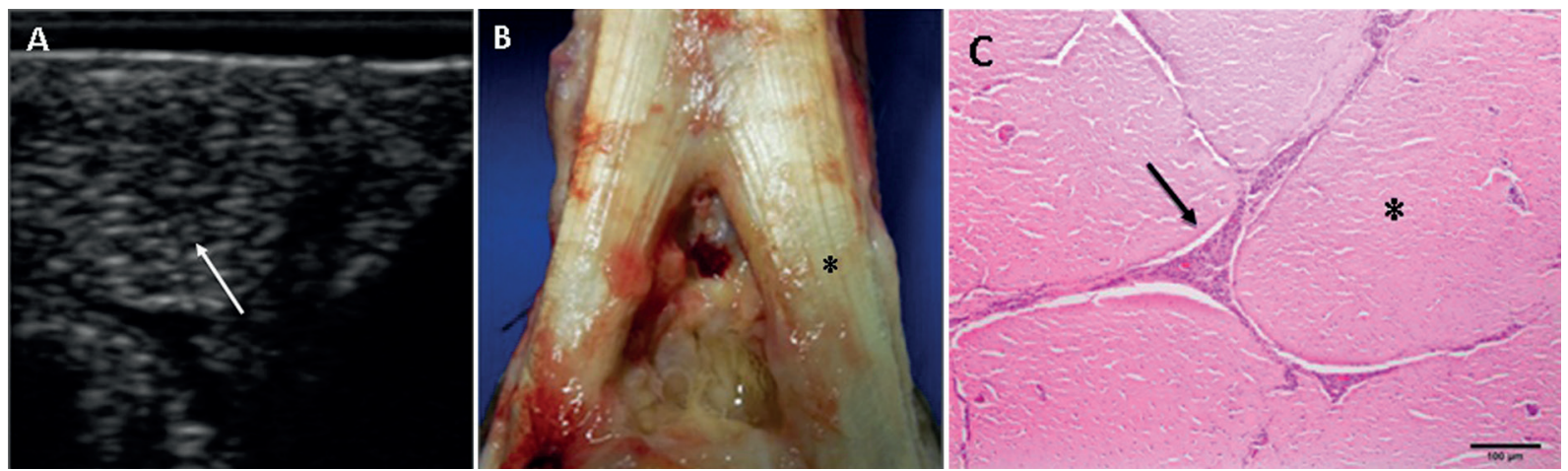

Fig.5. (A) Secção ultrassonográfica transversal do ramo medial do LS [seta]. Medial para a esquerda e lateral para a direita. (B) Ramo medial do LS [asterisco]. (C) Secção histológica transversal mostrando o arranjo em fascículos do LS circundado por tecido conjuntivo frouxo [seta] e o arranjo das fibras colágenas [asterisco].
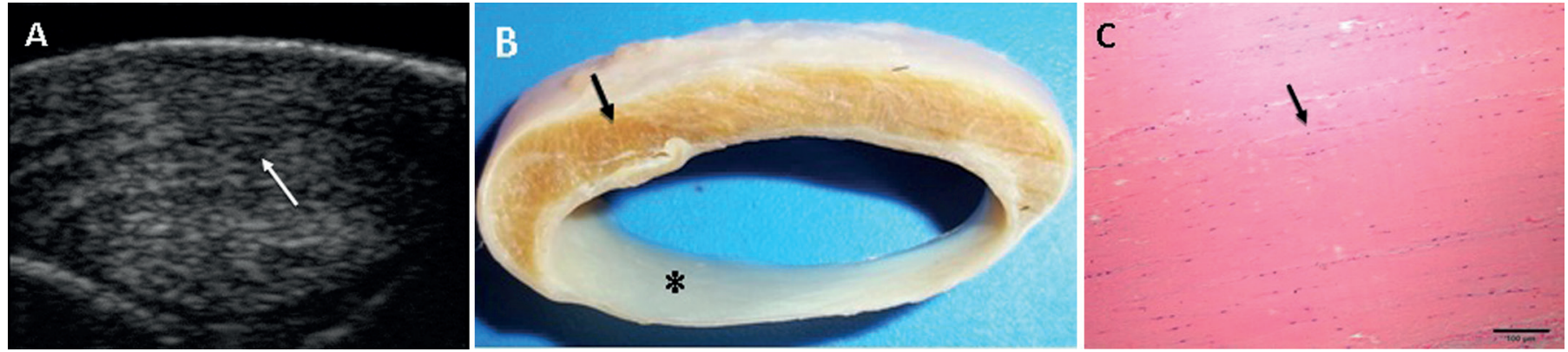

Fig.6. (A) Secção ultrassonográfica transversal da face palmar da articulação MF. Medial para a esquerda e lateral para a direita. 0 ecogênico TFDS [seta]. (B) Camada peritendinosa do TFDS [seta] e manica flexora [asterisco]. (C) Secção histológica longitudinal do TFDS. Tenócitos intercalados por fibras colágenas [seta].

da articulação MF e contêm vasos circundados por tecido conectivo. Eles apresentam coloração branca amarelada (Fig.5B), aspecto denso e arranjo linear das fibras similar aos tendões. A entrada vascular ocorre entre as fáscias que circundam seus fascículos (Fig.5C) e com células acompanhando a orientação das fibras colágenas chamadas de desmócitos.

\section{Face palmar}

$\mathrm{Na}$ abordagem transversal da face palmar da articulação MF, abaixo da pele se visualiza tecido conectivo regular denso e em seguida o LAP. O LAP é visualizado como uma faixa hipoecogênica que cobre o TFDS e se liga ao mesmo por uma estrutura hiperecogênica chamada mesotendão. 0 LAP se insere nos bordos dos sesamoides proximais e se estende lateral e medialmente aos bordos do LI. Ossos sesamoides proximais, LAP e LI formam um canal inelástico por onde passam os tendões flexores chamado de canal do boleto. O LAP é difícil de ser identificado na imagem ultrassonográfica porque a sua espessura na maioria dos casos é inferior a $1 \mathrm{~mm}$. Devido à hipoecogenicidade da bainha sinovial se obtém melhor definição do LAP e do TFDS afastando o transdutor medial ou lateralmente em relação ao eixo do membro. A coloração do LAP variou de branco perolado, branco amarelado a amarelo cinzento. Não houve relação entre variações na coloração e alterações ultrassonográficas ou histológicas. No exame histológico, as fibras colágenas do LAP apresentaram orientação em ondas paralelas. Havia quantidade variável de tecido conectivo regular denso entre o LAP e a pele. Macroscopicamente o espessamento do LAP em condições patológicas está acompanhado a áreas de aderência entre a bainha sinovial e o TFDS.

0 TFDS na face palmar da articulação MF adota um formato plano e conforme a movimentação lateral ou medial do transdutor ele se torna mais amplo (Fig.6A). Ele recobre o TFDP e o envolve por meio de uma estrutura fibrocartilaginosa chamada de manica flexora que permite o deslizamento destas estruturas durante a fase de hiperextensão da articulação MF, sem que ocorra aderência entre os tendões flexores. A arquitetura do TFDS se caracteriza por ecos longilíneos na secção ultrassonográfica transversal do tendão. Já o TFDP produz ecos pontuais com ecogenicidade maior, formato oval e bordos bem delimitados e lisos. Macroscopicamente a face palmar do TFDP que está em contato com o TFDS é lisa. Anatomicamente os bordos lateral e medial do TFDS emitem uma continuação com formato semelhante a uma faixa formando um anel que envolve o TFDP (Fig.6B). 0 conjunto das fibras tendíneas forma fascículos facilmente identificados no corte transversal do tendão e, organizadas de forma paralela sendo envolvidas por tecido conectivo. A cor varia de branco perolado a amarelo claro. Microscopicamente os tenócitos na secção transversal estão agrupados linearmente ao longo das fibras tendíneas (Fig.6C). Tecido conectivo regular denso envolve as fibras e desta forma ocorre o agrupamento em fascículos. Já na secção longitudinal o arranjo das fibras é linear.

O LI ou ligamento palmar é identificado como uma estrutura fina, ecogênica que ocupa o espaço de 3 a $6 \mathrm{~mm}$ 
formado pelos ossos sesamoides proximais. Macroscopicamente é uma estrutura fibrocartilaginosa que cobre os ossos sesamoides proximais sendo mais espessa no centro e se tornando progressivamente mais fina em direção aos bordos. Microscopicamente apresenta disposição fibrilar muito semelhante à parte superficial ou longa do LC late$\mathrm{ral} / \mathrm{medial}$.

\section{DISCUSSÃO}

A avaliação anatômica macroscópica e histológica foram os métodos utilizados como referência para avaliar a sensibilidade da técnica ultrassonográfica na articulação MF. Estas avaliações permitiram a caracterização da cartilagem articular, cápsula articular, tendões flexores, LAP, LCs, LS e LI sadios. Estas são estruturas frequentemente afetadas por alterações traumáticas e degenerativas adquiridas em decorrência da modalidade esportiva, tipo de criação e manejo dos animais. A associação destas diferentes técnicas de avaliação contribui com informações que tornam a interpretação do exame ultrassonográfico e, portanto, o diagnóstico clínico, mais preciso.

A cartilagem articular aparece como uma linha regular hipoecogênica localizada entre a membrana ou fluído sinovial e o osso subcondral hiperecogênico medindo 0,5 a $1 \mathrm{~mm}$ (Denoix 2009). Vanderperren et al. (2012) observaram que alterações ultrassonográficas do aspecto dorsal do boleto são caracterizadas por formações de osteófitos e por anormalidades de superfície óssea subcondral que variavam de pequenas indentações a severas irregularidades. Foi observado neste estudo, que a espessura da cartilagem articular deve ser avaliada ultrassonograficamente em toda a sua extensão, pois a sua diminuição pode indicar fibrilação ou erosão cartilaginosa. Histologicamente é possível diferenciar facilmente as três camadas da cartilagem articular contendo condrócitos de diferentes formas em cavalos adultos (Mcllwraith 2001). De Bastiani et al. (2014) observaram que quando ocorre perda cartilaginosa, ela inicia na camada superficial se estendendo posteriormente até a camada profunda com possível exposição do osso subcondral. Baseado na avaliação anatômica macroscópica do presente estudo, a cartilagem articular deve apresentar a superfície brilhante e recobrir toda a extensão do osso subcondral do côndilo do McIII sem apresentar fissuras. Sendo esta uma característica importante, pois permite estimar a integridade da cartilagem articular. A presença de irregularidades ósseas, fissuras cartilaginosas e formação de osteófitos é compatível com alteração patológica da mesma. A fibrilação cartilaginosa representa a perda progressiva das camadas da cartilagem chegando, em muitos casos, à eburnação da mesma e a consequente exposição do osso subcondral (De Bastiani et al. 2014). 0 osso subcondral quando lesionado por processos traumáticos ou inflamatórios, acarreta lesão secundária da cartilagem articular devido à falta de suporte ósseo com liberação de citocinas inflamatórias (Lajeunesse \& Reboul 2003, McIlwraith 2005). Uma vez degradada, a cartilagem articular não possui a capacidade de autorregeneração e nos casos onde houver perda de cartilagem com exposição do osso subcondral, ocorrerá a formação de tecido cicatricial fibroso (Hurtig et al. 1998). No presente estudo somente foram selecionadas cartilagens articulares que não apresentassem as alterações descritas anteriormente. 0 número reduzido de estruturas selecionadas se deve ao fato de que os espécimes foram obtidos em abatedouro para onde são destinados cavalos de descarte e a degeneração cartilaginosa é encontrada com frequência na articulação MF equina.

Nas secções ultrassonográficas longitudinais e transversais da face dorsal da articulação MF, a cápsula articular se localiza entre os tendões extensores dorsal e lateral (hipoecogênicos), a cartilagem articular anecóica e o McIII hiperecogênico subjacente (Denoix et al. 1997). 0 espessamento da cápsula articular (acima de 2 a $3 \mathrm{~mm}$ ) foi um achado ultrassonográfico comum e confirmado macroscopicamente utilizando-se o paquímetro. Este espessamento, quando bilateral e não acompanhado de outras alterações, parece ser uma variação anatômica normal. Uma estrutura importante a ser avaliada é a camada dorsal da cápsula articular, que se encontra em íntimo contato com a membrana sinovial, pois o avermelhamento e espessamento desta estrutura é considerado uma indicação de patologia. A camada interna da cápsula articular deve ser lisa e brilhante, podendo apresentar vilosidades. Geralmente a cápsula articular possui uma forma assimétrica no seu aspecto lateral e medial e está localizada dorsolateral e dorsomedial à crista sagital do côndilo metacarpiano (Denoix 1996).

Os LC são facilmente identificados quando se inicia o exame, localizando-os no plano sagital para em seguida avaliá-los no plano transversal. Ambas as partes superficial (longa) e profunda (curta) do LC apresentam fibras paralelas e espessura semelhante entre os aspectos medial e lateral da articulação na secção transversal (Reef 1998). Segundo Vanderperren et al. (2008), a parte superficial ou longa se origina na face distal do McIII e segue distalmente se inserindo na face proximal lateral/medial da primeira falange. A parte profunda ou curta é triangular e se origina na fossa condilar abaxial correndo oblíqua na direção palmar distal e se inserindo na primeira falange e ossos sesamoides. Desvios na conformação axial do membro podem predispor a uma sobrecarga articular e à maior tensão sobre o LC resultando no seu espessamento (Yovich et al. 1987). Alterações na ecogenicidade acompanhadas de espessamento e da presença de osteófitos articulares são achados anormais do LC. Porém, como visto neste estudo, o espessamento por si só não significa uma alteração patológica deste ligamento.

Na região distal do McIII, o LS se divide em dois ramos distintos adotando a forma de halteres na imagem transversal. Devido à refração resultante da sombra criada pelos bordos dos tendões flexores, não se identifica os ramos distais do LS de forma adequada a partir do aspecto palmar do membro (Smith 2008). Nas imagens longitudinais as fibras aparecem dispostas em arranjo linear e em íntimo contato com o osso sesamoide proximal correspondente. Irregularidades da superfície óssea dos sesamoides proximais juntamente com modificações na ecogenicidade e tamanho podem ser indicativos de patologia dos mesmos.

O LAP é espesso na secção transversal, tornando-se 
mais fino na sua inserção lateral e medial na superfície flexora dos ossos sesamoides proximais. As superfícies flexoras aparecem neste local como duas linhas curtas, ligeiramente convexas e hiperecogênicas, produzindo sombras acústicas na parte dorsal (Seignour et al. 2012). No exame macroscópico, a inserção do LAP está fortemente aderida aos ossos sesamoides proximais e seu afinamento é visível. 0 espessamento do LAP associado à presença de áreas de aderência ao TFDS resulta em alterações histopatológicas do LAP e do TFDS (De Bastiani et al. 2014). 0 transdutor deve ser movido lateral e medialmente para obter imagens da inserção do LAP nos sesamoides proximais. Segundo Smith (2008), isto facilita a diferenciação entre o LAP e o tendão devido à hipoecogenicidade da bainha sinovial. Ultrassonograficamente, o espessamento do tecido conectivo regular denso não deve ser confundido com patologias de LAP.

$\mathrm{Na}$ face proximal dos ossos sesamoides proximais, o TFDS envolve o TFDP, formando um anel chamado de manica flexora. $\mathrm{O}$ aspecto distal da manica flexora está localizado abaixo do LAP (Wilderjans 2008). Na relação entre estas estruturas a presença de aderências é indicativa de alteração. 0 bordo palmar do TFDP deve ser bem delimitado e liso sem apresentar fissuras verticais. Na região metacarpo/metatarsiana, o TFDP adquire forma oval e se torna mais largo e triangular distalmente no aspecto palmar/plantar da articulação MF. Juntamente com a manica flexora, o TFDP desliza pelo scutum proximal, composto pelo LAP e os dois ossos sesamoides proximais (Denoix 2000). Por isto, é de extrema importância que a avaliação das estruturas que compõem a face palmar da articulação MF seja realizada em conjunto. Em condições biomecânicas normais, a articulação MF pode ser flexionada e estendida durante o exame ecográfico permitindo observar o movimento simultâneo destas estruturas e a eventual presença de aderências. A coloração dos tendões e ligamentos no estudo macroscópico, variou de branco perolado a amarelo claro e vermelho acinzentado. Segundo Gartner \& Hiatt (1997), o amadurecimento dos tendões pode ser responsável por mudanças na sua cor bem como o aparecimento de zonas centrais marrom escuras ou vermelho acinzentadas. Como não foi possível obter informações sobre a idade dos animais, não se estabeleceu esta relação no estudo.

\section{CONCLUSÕES}

Os achados macroscópicos e histológicos da articulação MF normal neste objeto de estudo descrevem parâmetros como a arquitetura, tamanho, forma e coloração de tendões, ligamentos, cápsula e cartilagens articulares. Características estas, que servem como base para uma interpretação ultrassonográfica correta contribuindo desta forma, para um diagnóstico por imagem de excelência.

O espessamento da cápsula articular e do LAP podem ser considerados como uma variação anatômica de cada equino.

Agradecimentos.- Os autores agradecem ao Frigorífico Foresta pela contribuição neste estudo, por meio do fornecimento dos espécimes de membros torácicos equinos.

\section{REFERÊNCIAS}

Barone R. 1989. Articulations metacarpal-phalangiennea, p.187-204. In: Ibid. (Ed.), Anatomies des Mamiferes Domestiques. Tome 2. Arthrologie et Myologie. Vigot, Paris.

De Bastiani G., De La Côrte F.D., Brass K.E., Kommers G.D. \& Denoix J.M. 2014. Association of ultrasound and anatomopathologic findings of equine metacarpophalangeal lesions. J. Equine Vet. Sci. 34:1218-1225.

Denoix J.M. 1996. Ultrasonography examination in the diagnosis of joint disease, p.165-202. In: Mcilwraith C.W. \& Trotter G.W. (Eds), Joint Disease in the Horse. Saunders, Philadelphia.

Denoix J.M., Busoni V. \& Olalla M.J. 1997. Ultrasonographic examination of the proximal scutum in the horse. Equine Vet. J. 29:136-141.

Denoix J.M. 2000. The equine distal limb, p.243-376. In: Ibid. (Ed.), Atlas of Clinical Anatomy and Comparative Imaging. Manson Publishing, London.

Denoix J.M. 2009. Ultrasonographic examination of joints in horses: a live demonstration. Proc. 11th International Congress World Equine Veterinary Association, Guarujá, SP, Brazil, p.1-10.

Gartner L.P. \& Hiatt J.L. 1997. Color Textbook of Histology. W.B. Saunders, Philadelphia, p.92-108.

Hurtig M.B., Fretz P.B., Doige C.E. \& Schnurr D.L. 1998. Effects of lesion size and location on equine articular cartilage repair mark. Can. J. Vet. Res. 59:137-146.

Lajeunesse D. \& Reboul P. 2003. Subchondral bone in osteoarthritis: a biologic link with articular cartilage leading to abnormal remodeling. Rheumatology 15:628-633.

Mcllwraith C.W. 2001. Disease processes of synovial membrane, fibrous capsule, ligaments, and articular cartilage. Proc. 47th Annual Convention American Association of Equine Practioners. San Diego, CA, p.142-156.

Mcllwraith C.W. 2005. From arthroscopy to gene therapy: 30 years of looking in joints. Am. Assoc. Equine Pract. 51:65-113.

Reef V.B. 1998. Musculoskeletal ultrasonography, p.39-79. In: Ibid. (Ed.), Equine Diagnostic Ultrasound. W.B. Saunders, Philadelphia.

Seignour M., Coudry V., Norris R. \& Denoix J.M. 2012. Ultrasonographic examination of the palmar/plantar aspect of the fetlock in the horse: Technique and normal images. Equine Vet. Educ. 24:19-29.

Smith R. 2008. Tendon and ligament injury. Proc. 54th Annual Convention American Association of Equine Practitioners, San Diego, p.475-501.

Wilderjans H. 2008. Tenoscopy of the digital flexor tendon sheath. Proc. 10th International Congress World Equine Veterinary Association, Moscow, p.182-187.

Yovich J.V., Turner A.S., Stashak T.S. \& McIlwraith C.W. 1987. Luxation of the metacarpophalangeal and metatarsophalangeal joints in horses. Equine Vet. J. 19:295-298.

Vanderperren K., Ghaye B., Snaps F.R. \& Saunders J.H. 2008. Evaluation of computed tomographic anatomy of the equine metacarpophalangeal joint. Am. J. Vet. Res. 69:631-638.

Vanderperren K., Gielen I., Caelenberg A.V., Van der Vekens E., Raes E.V., Hauspie S., Van Bree H. \& Saunders J.H. 2012. Ultrasonographic appearance of bony abnormalities at the dorsal aspect of the fetlock joint in geriatric cadaver horses. Vet. J. 193:129-134. 